\title{
The 8th TNM classification for oral squamous cell carcinoma: What is gained, what is lost, and what is missing ${ }^{\text {th }}$
}

\author{
Davide Mattavelli ${ }^{\mathrm{a}, *, 1}$, Marco Ferrari ${ }^{\mathrm{a}, \mathrm{b}, 1}$, Stefano Taboni $^{\mathrm{a}}$, Riccardo Morello ${ }^{\mathrm{a}}$, Alberto Paderno ${ }^{\mathrm{a}}$, \\ Vittorio Rampinelli ${ }^{\mathrm{a}}$, Francesca Del Bon ${ }^{\mathrm{a}}$, Davide Lombardi ${ }^{\mathrm{a}}$, Alberto Grammatica ${ }^{\mathrm{a}}$, Paolo Bossi ${ }^{\mathrm{c}}$, \\ Alberto Deganello ${ }^{\mathrm{a}}$, Cesare Piazza ${ }^{\mathrm{d}}$, Piero Nicolai ${ }^{\mathrm{b}}$ \\ ${ }^{\text {a }}$ Unit of Otorhinolaryngology - Head and Neck Surgery, Department of Medical and Surgical Specialties, Radiological Sciences and Public Health, University of Brescia, \\ Brescia, Italy \\ ${ }^{\mathrm{b}}$ Section of Otorhinolaryngology - Head and Neck Surgery, Department of Neurosciences, University of Padua, Padua, Italy \\ ${ }^{\mathrm{c}}$ Medical Oncology Unit, Department of Medical and Surgical Specialties, Radiological Sciences and Public Health, University of Brescia, Brescia, Italy \\ ${ }^{\mathrm{d}}$ Department of Otorhinolaryngology, Maxillofacial and Thyroid Surgery, Fondazione IRCCS National Cancer Institute of Milan, Department of Oncology and \\ Oncohematology, University of Milan, Milan, Italy
}

\section{A R T I C L E I N F O}

\section{Keywords:}

Oral cancer

Oral squamous cell carcinoma

8th TNM edition

Depth of invasion

Perineural invasion

Nodal metastasis

Number of positive nodes

\begin{abstract}
A B S T R A C T
Objectives: The 8th TNM edition remarkably changed the classification of $\mathrm{T}$ and $\mathrm{N}$ categories for oral squamous cell carcinoma (OSCC). The present study aims at evaluating the improvement in prognostic power compared to the 7th edition, pros and cons of the modifications, and parameters deserving consideration for further implementations.

Materials and methods: All OSCCs treated with upfront surgery at our institution between 2002 and 2017 were included. Demographics, clinical-pathological and treatment variables were retrieved. All tumors were classified according to both the 7th and 8th TNM edition, and patients were grouped according to the shift in T category and stage. Survivals were calculated with the Kaplan-Meier method. Univariate and multivariate analysis were carried out. Receiver Operating Characteristics (ROC) curve analyses were performed to find the best cut-off of DOI (in patients with DOI $>10 \mathrm{~mm}$ ) and number of involved nodes (in positive neck patients).

Results: 244 patients were included. T, N categories, and stage changed in $59.2 \%, 20.5 \%$, and $49.1 \%$ patients, respectively; $41.5 \%$ of patients were upstaged. The new $\mathrm{T}$ classification well depicted prognosis according to OS. Five-year overall (OS), disease-specific, recurrence-free (RFS) survivals were $60.5 \%, 70.9 \%, 59.8 \%$, respectively. According to ROC curves, DOI $>20 \mathrm{~mm}$ and 4 positive nodes were the best cutoffs for OS and RFS.

Conclusion: The novelties introduced in 8th TNM edition were positive. DOI $>20 \mathrm{~mm}$ for T4 definition and number of positive nodes $(0,<4,4$ or more) for $\mathrm{N}$ classification emerged as the most urgent factors to be implemented.
\end{abstract}

\section{Introduction}

Oral cavity squamous cell carcinoma (OSCC) accounts for $8 \%$ of all malignancies and $30 \%$ of head and neck cancers [1]. Its incidence is steadily increasing worldwide and 5-year survival estimates remain unchanged despite significant improvements in diagnostic techniques and treatment strategies [1,2]. The tumor, node, and metastasis (TNM) staging system is the principal criterion to describe and stage tumor extension, as well as to guide, evaluate, and compare therapeutic strategies based on internationally-accepted guidelines [3,4]. The 8th Edition of the American Joint Committee on Cancer (AJCC) TNM staging system has been actively implemented since January 2018 [5]. Compared with the 7th Edition, OSCC staging criteria were relevantly modified. In particular, depth of invasion (DOI) and extranodal extension (ENE) were introduced as parameters to define the $\mathrm{T}$ and $\mathrm{N}$ category, respectively [6-10].

\footnotetext{
This research did not receive any specific grant from funding agencies in the public, commercial, or not-for-profit sectors. Authors have not any financial and personal relationships with other people or organizations to disclose.

* Corresponding author at: Unit of Otorhinolaryngology-Head and Neck Surgery, Spedali Civili of Brescia, University of Brescia, Piazzale Spedali Civili 1, 25123 Brescia, Italy.

E-mail address: davide.mattavelli@unibs.it (D. Mattavelli).

${ }^{1} \mathrm{DM}$ and MF equally share the first authorship.
} 
The present study is aimed at evaluating the changes in classification, prognostic implications, and possible weaknesses of the novel TNM classification of OSCC based on a homogeneous cohort of patients treated over a 15-year period at a tertiary academic institution.

\section{Materials and methods}

\section{Patient selection}

All patients with OSCC treated at the Unit of Otorhinolaryngology Head and Neck Surgery of the University of Brescia from January 2002 to August 2017 were included. All patients underwent upfront surgery including resection of the primary tumor and neck dissection. Exclusion criteria were: (1) distant metastasis at presentation; (2) previous and/or synchronous head and neck cancer; (3) follow-up unavailable; (4) history of cancer within the last 5 years (any site, any stage). During the study period, all pathological specimens were examined by dedicated head and neck pathologists; both DOI and ENE were consistently reported according to internationally accepted criteria. All OSCCs could be appropriately staged on the base of pathological reports according to both the 7th and 8th editions of the TNM classification. The study was conducted in accordance with the guidelines of the Declaration of Helsinki and the principles of Good Clinical Practice.

\section{Treatment and follow-up}

Each case was discussed in the multidisciplinary head and neck tumor board at our institution. Indications for treatment were given on a case-by-case basis according to the National Comprehensive Cancer Network (NCCN) guidelines available at the time of diagnosis. Adjuvant radiotherapy (RT) followed a standardized fractionation regimen (60-66 Gy on high-risk volume and 50-54 Gy on low-/intermediaterisk volume, in daily fractions of 1.8-2 Gy). Concomitant chemotherapy consisted of cisplatin either $100 \mathrm{mg} / \mathrm{m}^{2}$ every 3 weeks or $40 \mathrm{mg} / \mathrm{m}^{2}$ weekly.

In the first 2 years after treatment, the follow-up schedule included clinical evaluation every 2 months and imaging assessment (computed tomography [CT] or magnetic resonance [MR] together with ultrasonography of the neck) every 4 months. Clinical and imaging examinations were subsequently performed every 6 months up to the 5th year and yearly thereafter $[11,12]$. CT of the thorax and abdomen, positron emission tomography (PET), or PET-CT were performed yearly during the first 5 years after treatment in patients deemed at high-risk of recurrence.

\section{Statistical analysis}

Statistical analysis was performed using a commercially available software (XLSTAT add-on for Microsoft Excel, version 2017.6.0; Addinsoft SARL, Paris, France). The following variables were included: age, gender, subsite of oral cavity (buccal mucosa, alveolar ridges, hard palate, tongue, floor of mouth) [13], tumor differentiation (well, moderate, or poor) [14], 7th and 8th TNM classification and stage, treatment, DOI, distance between excision margins and invasive front of the tumor, margin status, presence of bone, perineural, vascular invasion, ENE, count of involved and removed nodes, and nodal ratio (defined as the ratio between positive and removed nodes).

Descriptive statistics were performed obtaining distribution of categorical variables and mean, median, range, and interquartile range for continuous variables. A contingency table was obtained matching the 7th and 8th Edition-based T, N categories, and UICC/AJCC stage. According to the modifications of the $\mathrm{T}$ category observed comparing the 7th with the 8th edition, each case was included in one of the following groups:

- $\mathrm{T}_{1 / 2 \rightarrow 1 / 2}$ : tumors remaining $\mathrm{T} 1$ or $\mathrm{T} 2$ in both editions;
- $\mathrm{T}_{4 \mathrm{a} \rightarrow 1 / 2}$ : tumors downstaged from $\mathrm{T} 4 \mathrm{a}$ to $\mathrm{T} 1$ or $\mathrm{T} 2$;

- $\mathrm{T}_{1 / 2 \rightarrow 3}$ : tumors upstaged from T1 or T2 to T3;

- $\mathrm{T}_{4 \mathrm{a} \rightarrow 3}$ : tumors downstaged from T4a to T3;

- $\mathrm{T}_{4 \mathrm{a} \rightarrow 4 \mathrm{a}}$ : tumors remaining $\mathrm{T} 4 \mathrm{a}$ in both Editions.

According to the modification of the assigned UICC/AJCC stage observed comparing the 7th to the 8th edition, each case was included in one of the following groups:

- I/II $\rightarrow$ I/II: tumors remaining stage I or II in both editions;

- II $\rightarrow$ III: tumors upstaged from stage II to stage III;

- III $\rightarrow$ III: tumors remaining stage III in both editions;

- IV $\rightarrow$ II: tumors downstaged from stage IV to stage II;

- IV $\rightarrow$ III: tumors downstaged from stages IVA/B to stage III;

- IV $\rightarrow$ IV: tumors remaining stage IVA or IVB in both editions;

Groups including less than 10 patients were excluded from statistical analysis. Associations between the modification of T, $\mathrm{N}$ categories, and DOI were assessed by Chi-square, Fisher's exact, Kruskal-Wallis, and/or Steel-Dwass-Critchlow-Fligner tests, as appropriate.

Overall (OS), disease-specific (DSS), recurrence-free (RFS), local recurrence-free (LRFS), regional recurrence-free (RRFS), and distant recurrence-free (DRFS) survivals were calculated with the Kaplan-Meier method. For each survival estimate, the entry time was the date of conclusion of treatments (surgery or adjuvant therapies). Survival analyses were made by univariate models based on log-rank test (categorical variables) or Cox proportional hazard model (continuous variables), as appropriate.

Variables with statistical significance at univariate analysis were considered eligible for the multivariate Cox proportional hazard model. In line with Harrell's guidelines [15], the maximum number of factors admitted in the multivariate model was calculated for each survival as $10 \%$ of observed events; if needed, a further selection of variables was made based on clinical relevance and redundancy of information. Only the 8th TNM edition was included in the prognostic model.

Finally, Receiver Operating Characteristics (ROC) curve analyses were performed considering death from any cause and recurrence of disease as events, and DOI (in patients with DOI $>10 \mathrm{~mm}$ ) and number of involved nodes (in positive neck patients) as the tests. Patients alive and free of disease with less than 6 months of follow-up were excluded from the analyses, respectively.

A Kaplan-Meier analysis with log-rank test of OS and RFS was performed using the cut-off values extrapolated from ROC curves. The level of significance was set at 0.05 for all statistical tests.

\section{Results}

\section{Description of the series}

The study included 244 patients. Complete demographic, clinical, and pathologic data are reported in Table 1. Male-to-female ratio was $1.7: 1$ with a median age of 64.1 years. The mobile tongue $(50.4 \%)$ and floor of the mouth $(20.9 \%)$ were the most frequently involved subsites. Lymph node metastases were diagnosed in 112 (45.7\%) patients, with ENE reported in 56 (22.9\%). Margins were clear in 139 (57.0\%) patients, close in 66 (27.0\%), and involved in 39 (16.0\%). Adjuvant RT was offered to 146 patients $(60.1 \%)$. Sixty patients $(24.6 \%)$ also received concomitant platinum-based chemotherapy.

Mean follow-up was 32.8 months (range, 1.1-181.1). Tumor recurrence occurred in 86 (35\%) patients: 52 (21.3\%) local, 49 (20.1\%) regional, and $32(13.1 \%)$ at distant sites. Overall, 90 deaths were recorded, and 58 were cancer-related. Five-year estimates of OS, DSS, RFS, LRFS, RRFS, and DRFS were 60.5\%, 70.9\%, 59.8\%, 74.3\%, 74.5\%, and $83.9 \%$, respectively. 
Table 1

Demographics and clinical-pathologic features of the series.

\begin{tabular}{lll}
\hline Demographics and clinical-pathologic variables & N (\%) \\
\hline Gender & Male & $153(62.7 \%)$ \\
& Female & $91(37.3 \%)$ \\
Mean age (years, range) & & $63.8(26-98)$ \\
Subsite & Tongue & $123(50.4 \%)$ \\
& Floor of the mouth & $51(20.9 \%)$ \\
& Retromolar trigone & $25(10.2 \%)$ \\
& Alveolar ridge & $26(10.6 \%)$ \\
& Buccal mucosa & $19(7.8 \%)$
\end{tabular}

Surgical Treatment

\begin{tabular}{lll}
\hline $\begin{array}{l}\text { Transoral resection } \\
\text { Pull-through resection }\end{array}$ & & $62(25.1 \%)$ \\
Neck dissection & & $182(74.9 \%)$ \\
& Selective & $133(54.5 \%)$ \\
& Comprehensive & $111(45.7 \%)$ \\
& Unilateral & $171(70.4 \%)$ \\
& Bilateral & $72(29.6 \%)$
\end{tabular}

Histopathological data

\begin{tabular}{lll}
\hline Surgical margins & Negative & $139(57.0 \%)$ \\
& Close & $66(27.0 \%)$ \\
Grading & G1 & $39(16.0 \%)$ \\
& G2 & $85(34.8 \%)$ \\
G3 & $132(54.1 \%)$ \\
Mean depth of infiltration (range) & $25(10.2 \%)$ \\
Perineural invasion & Absent & $13.5 \mathrm{~mm}(0.5-92 \mathrm{~mm})$ \\
& Present & $116(47.7 \%)$ \\
Lymphovascular invasion & Absent & $126(52.3 \%)$ \\
& Present & $175(72.0 \%)$ \\
Mean number of removed nodes (range) & $68(28.0 \%)$ \\
Median number of nodal metastases (range) & 45.7 nodes (7-119) \\
Mean lymph node ratio (range) & & 1.6 nodes (0-20) \\
Extranodal extension & Absent & $3.5 \%(0-20 \%)$ \\
& Present & $186(76.9 \%)$ \\
Adjuvant treatments & $56(21.1 \%)$ \\
\hline $\begin{array}{l}\text { Adjuvant radiotherapy } \\
\text { Concomitant chemotherapy }\end{array}$ & & \\
\hline
\end{tabular}

\section{TNM and stage modifications}

Modifications of T, $\mathrm{N}$ categories, and stage are reported in Table 2. The analysis of pT category changes was feasible in 191 (78.3\%) patients. Sixty-nine $(36.1 \%)$ were reassigned to a lower pT category, mostly including cases of downstaging from pT4a to pT3. Conversely, $44(23.1 \%)$ tumors were reassigned to a higher pT category, mostly due to a shifting from pT2 to pT3. In $40.8 \%$ of cases the pT category remained unchanged.

Analysis of pN category changes was feasible in all cases. In 50 (20.5\%) patients, the nodal status was upstaged to pN3b due to ENE, which upstaged only 2 cases from pN1 to pN2a.

The analysis of stage modifications was definable for 205 (84.0\%) cases. As a consequence of $\mathrm{T}$ and $\mathrm{N}$ shifting, stage migration was recorded in more than half of patients: 35 cases $(17.1 \%)$ were downstaged, and 85 (41.5\%) were upstaged. In particular, 20 (9.8\%) patients shifted from an early (I-II) to an advanced stage (III-IV) due to an upstage in T category, and $56(27.3 \%)$ patients shifted from stage IVA to stage IVB due to an upstage in N category (N3b). Overall, only 67 (35.1\%) cases with all information available showed no change in terms of both $\mathrm{T}$ and $\mathrm{N}$ categories.
Table 2

Contingency table of the modifications of pathological $\mathrm{T}$ and $\mathrm{N}$ category and stage classification between 7th and 8th edition of TNM.

\begin{tabular}{|c|c|c|c|c|c|c|c|c|}
\hline \multirow[t]{2}{*}{ Total patients $(\mathrm{N}=191)$} & & \multicolumn{7}{|c|}{ pT classification (8th edition) } \\
\hline & & $\mathrm{T} 1$ & & $\mathrm{~T} 2$ & & T3 & $\mathrm{T} 4$ & \\
\hline \multirow[t]{4}{*}{ pT classification (7th edition) } & $\mathrm{T} 1$ & 21 & & 13 & & 5 & 0 & \\
\hline & $\mathrm{T} 2$ & 3 & & 23 & & 26 & 0 & \\
\hline & $\mathrm{T} 3$ & 0 & & 0 & & 2 & 0 & \\
\hline & $\mathrm{T} 4$ & 0 & & 10 & & 56 & 32 & \\
\hline \multirow[t]{2}{*}{ Total patients $(\mathrm{N}=244)$} & & \multicolumn{7}{|c|}{ pN classification (8th edition) } \\
\hline & & NO & N1 & $\mathrm{N} 2 \mathrm{a}$ & $\mathrm{N} 2 \mathrm{~b}$ & $\mathrm{~N} 2 \mathrm{c}$ & N3a & N3b \\
\hline \multirow[t]{6}{*}{$\mathrm{pN}$ classification (7th edition) } & No & 131 & 0 & 0 & 0 & 0 & 0 & 0 \\
\hline & N1 & 0 & 29 & 6 & 0 & 0 & 0 & 0 \\
\hline & $\mathrm{N} 2 \mathrm{a}$ & 0 & 0 & 2 & 0 & 0 & 0 & 1 \\
\hline & $\mathrm{N} 2 \mathrm{~b}$ & 0 & 0 & 0 & 21 & 0 & 0 & 37 \\
\hline & $\mathrm{N} 2 \mathrm{c}$ & 0 & 0 & 0 & 0 & 4 & 0 & 12 \\
\hline & N3 & 0 & 0 & 0 & 0 & 0 & 0 & 0 \\
\hline \multirow[t]{2}{*}{ Total patients $(\mathrm{N}=206)$} & & \multicolumn{7}{|c|}{ Stage classification (8th edition) } \\
\hline & & I & I & & III & IVA & IV & \\
\hline \multirow{5}{*}{$\begin{array}{l}\text { Stage classification ( } 7 \text { th } \\
\quad \text { edition) }\end{array}$} & I & 15 & 9 & & 4 & 0 & 0 & \\
\hline & II & 2 & & 8 & 15 & 1 & 0 & \\
\hline & III & 0 & 0 & & 14 & 0 & 1 & \\
\hline & IVA & 0 & 3 & & 30 & 38 & 5 & \\
\hline & IVB & 0 & 0 & & 0 & 0 & 0 & \\
\hline
\end{tabular}

Impact of TNM and stage modifications on survival

Downstaged tumors $\mathrm{T}_{4 \mathrm{a} \rightarrow 1 / 2}$ and $\mathrm{T}_{4 \mathrm{a} \rightarrow 3}$ were associated with the highest rate of nodal metastasis ( $\mathrm{p}=0.0004)$, highest $\mathrm{N}$ category according to the 8th edition ( $\mathrm{p}=0.006$ ), highest number of nodal involvement $(\mathrm{p}=0.0002)$, and highest rate of ENE $(\mathrm{p}=0.001)$ (Table 3). $\mathrm{T}_{4 \mathrm{a} \rightarrow 3}$ OSCCs had the highest DOI (median, $19.5 \mathrm{~mm}$ ), which was significantly higher with respect to all other T-modification groups except for $\mathrm{T}_{4 \mathrm{a} \rightarrow 4 \mathrm{a}}$ tumors ( $\mathrm{p}<0.0001$ ) (Table 4).

Fig. 1 and Supplementary Fig. 1 describes the impact of $\mathrm{T}$ reclassification on survival. OS drastically decreased when comparing patients with $\mathrm{T}_{1 / 2 \rightarrow 1 / 2}$ tumors to all other patients. OS of patients with $\mathrm{T}_{4 \mathrm{a} \rightarrow 1 / 2}$ or $\mathrm{T}_{4 \mathrm{a} \rightarrow 4 \mathrm{a}}$ tumors continued to decrease at 5 years after treatment, whereas $\mathrm{T}_{1 / 2 \rightarrow 3}$ or $\mathrm{T}_{4 \mathrm{a} \rightarrow 3}$ OSCCs showed a constant OS of around $50 \%$ in the long-term $(\mathrm{p}=0.0003)$. DSS had a similar trend, except for the $\mathrm{T}_{4 \mathrm{a} \rightarrow 1 / 2}$ group, which showed a survival similar to $\mathrm{T}_{1 / 2 \rightarrow 3}$ or $\mathrm{T}_{4 \mathrm{a} \rightarrow 3}$ cases $(p=0.005)$. When focusing on RFS, $T_{1 / 2 \rightarrow 3}$ group aligned with the $\mathrm{T}_{1 / 2 \rightarrow 1 / 2}$ curve, while $\mathrm{T}_{4 \mathrm{a} \rightarrow 3}$ and $\mathrm{T}_{4 \mathrm{a} \rightarrow 1 / 2} / \mathrm{T}_{4 \mathrm{a} \rightarrow 4 \mathrm{a}}$ showed a stepwise decrease in survival rate $(\mathrm{p}=0.005)$.

Fig. 2 and Supplementary Fig. 2 focuses on stage modifications and survival. OS was worst for patients with IV $\rightarrow$ IV and IV $\rightarrow$ II tumors, while the long-term prognosis was similar for patients with $\mathrm{I} / \mathrm{II} \rightarrow \mathrm{I} / \mathrm{II}$, $\mathrm{I} / \mathrm{II} \rightarrow \mathrm{III}, \mathrm{III} \rightarrow \mathrm{III}$, and IV $\rightarrow$ III $(\mathrm{p}<0.0001)$. The DSS was 3 -tiered according to the stage: I/II $\rightarrow$ I/II, IV $\rightarrow$ II, I/II $\rightarrow$ III, IV $\rightarrow$ III tumors showed the best survival, III $\rightarrow$ III showed an intermediate outcome, and IV $\rightarrow$ IV did worse ( $<<0.0001$ ). RFS was highest for I/II $\rightarrow$ I/II and I/II $\rightarrow$ III, intermediate for IV $\rightarrow$ III, and lowest for IV $\rightarrow$ II, III $\rightarrow$ III, and IV $\rightarrow$ IV tumors ( $\mathrm{p}<0.0001$ ).

\section{Prognosticators}

The results of the univariate and multivariate analyses are summarized in Supplementary Tables 1 and 2. In multivariate analysis, T4a category was associated with decreased OS (OR $=12.78, \mathrm{CI}$ 1.39-117.79; $\mathrm{p}=0.025)$. DOI and perineural invasion were associated with decreased DSS (OR $=1.05$, CI 1.01-1.10; $\mathrm{p}=0.019)$ and DRFS $(\mathrm{OR}=2.40$, CI 1.10-5.23; $\mathrm{p}=0.028)$, respectively. 
Table 3

Summary of associations between T-reassignment and nodal disease load. ENE - Extranodal extension.

\begin{tabular}{|c|c|c|c|c|c|c|}
\hline $\mathrm{T}$ modification & $\mathrm{T}_{1 / 2 \rightarrow 1 / 2}$ & $\mathrm{~T}_{4 \mathrm{a} \rightarrow 1 / 2}$ & $\mathrm{~T}_{1 / 2 \rightarrow 3}$ & $\mathrm{~T}_{4 \mathrm{a} \rightarrow 3}$ & $\mathrm{~T}_{4 \mathrm{a} \rightarrow 4 \mathrm{a}}$ & $\mathrm{p}$-Value \\
\hline Patients with nodal metastasis (percentage) & $16 / 70(26.7 \%)$ & $6 / 10(60.0 \%)$ & $12 / 30(40.0 \%)$ & $37 / 56(66.1 \%)$ & $11 / 31(35.5 \%)$ & $0.0004^{*}$ \\
\hline \multirow[t]{4}{*}{ 8th edition $\mathrm{N}$ category (percentages) } & N0: $73.3 \%$ & N0: $40.0 \%$ & N0: $60.0 \%$ & N0: $33.9 \%$ & N0: $64.5 \%$ & $0.006^{*}$ \\
\hline & N1: $10.0 \%$ & N1: $10.0 \%$ & N1: $10.0 \%$ & $\mathrm{~N} 1: 12.5 \%$ & N1: $6.5 \%$ & \\
\hline & N2: $8.3 \%$ & N2: $0.0 \%$ & N2: $6.7 \%$ & N2: $17.9 \%$ & N2: $12.5 \%$ & \\
\hline & N3: $8.3 \%$ & N3: $50.0 \%$ & N3: $23.3 \%$ & N3: $35.7 \%$ & N3: $16.1 \%$ & \\
\hline Number of involved nodes (median; mean) & $0.0 ; 1.0$ & $1.5 ; 1.3$ & $0 ; 1.2$ & $2.0 ; 2.9$ & $0 ; 1.1$ & $0.0002^{\text {*i* }}$ \\
\hline Nodal metastasis with ENE (percentage) & $10.0 \%$ & $50.0 \%$ & $23.3 \%$ & $41.1 \%$ & $19.4 \%$ & $0.001^{* * * *}$ \\
\hline
\end{tabular}

* Chi-square.

** Kruskal-Wallis.

*** Fisher's exact test.

\section{Table 4}

Table summarizing the p-values of comparisons between T-modification groups in terms of depth of invasion (DOI), based on Kruskal-Wallis and Steel-DwassCritchlow-Fligner post-hoc tests.

\begin{tabular}{llllll}
\hline $\begin{array}{l}\mathrm{T} \text { modification } \\
\text { (median DOI) }\end{array}$ & $\begin{array}{l}\mathrm{T}_{1 / 2 \rightarrow 1 / 2} \\
(6.0 \mathrm{~mm})\end{array}$ & $\begin{array}{l}\mathrm{T}_{4 \mathrm{a} \rightarrow 1 / 2} \\
(9.0 \mathrm{~mm})\end{array}$ & $\begin{array}{l}\mathrm{T}_{1 / 2 \rightarrow 3} \\
(13.5 \mathrm{~mm})\end{array}$ & $\begin{array}{l}\mathrm{T}_{4 \mathrm{a} \rightarrow 3} \\
(19.5 \mathrm{~mm})\end{array}$ & $\begin{array}{l}\mathrm{T}_{4 \mathrm{a} \rightarrow 4 \mathrm{a}} \\
(17.0 \mathrm{~mm})\end{array}$ \\
\hline $\begin{array}{c}\mathrm{T}_{1 / 2 \rightarrow 1 / 2}(6.0 \mathrm{~mm}) \\
\mathrm{T}_{4 \mathrm{a} \rightarrow 1 / 2}\end{array}$ & 1 & 0.015 & $<0.0001$ & $<0.0001$ & $<0.0001$ \\
$\begin{array}{c}(9.0 \mathrm{~mm}) \\
\mathrm{T}_{1 / 2 \rightarrow 3}(13.5 \mathrm{~mm})\end{array}$ & 0.015 & 1 & 0.002 & $<0.0001$ & 0.294 \\
$\begin{array}{c}(13.5 \mathrm{~m} \rightarrow 3 \\
(19.5 \mathrm{~mm})\end{array}$ & $<0.0001$ & 0.002 & 1 & 0.004 & 0.860 \\
$\mathrm{~T}_{4 \mathrm{a} \rightarrow 4 \mathrm{a}}(17.0 \mathrm{~mm})$ & $<0.0001$ & $<0.0001$ & 0.004 & 1 & 0.536 \\
\hline
\end{tabular}

The presence of nodal metastasis (pN1 to pN3 categories) was related to lower RFS (OR $=6.73$, CI 2.62-17.25; $\mathrm{p}<0.0001)$, LRFS $(\mathrm{OR}=3.94$, CI 1.45-10.71; $\mathrm{p}=0.007)$, and RRFS (OR $=7.41$, CI 2.63-20.89; $\mathrm{p}<0.0001$ ), while the $\mathrm{pN} 3 \mathrm{~b}$ category was associated with worse OS (OR $=3.80$, CI 1.34-10.78; $\mathrm{p}=0.012)$, DSS $(\mathrm{OR}=5.42$, CI 1.36-21.6; $\mathrm{p}=0.017)$, and DRFS (OR $=4.57$, CI $1.50-13.91 ; \mathrm{p}=0.008$ ). The number of positive nodes was independently associated with a stepwise decrease of all outcomes. Adjuvant (chemo)RT was an independent protective factor in terms of $\mathrm{OS}(\mathrm{OR}=0.38$, CI $0.00-0.85 ; \mathrm{p}=0.019)$ and RFS (OR $=0.43$, CI $0.00-0.93 ; \mathrm{p}=0.032$ ).

ROC curve analysis showed that among patients with DOI $>10 \mathrm{~mm}$, DOI $\geq 22 \mathrm{~mm}$ was the cut-off value that provided the highest accuracy in terms of increased probability of death (area under the curve $[\mathrm{AUC}]=0.563 ; \mathrm{p}=0.343$ ) and recurrence (AUC $=0.622$; $\mathrm{p}=0.069)$. On the other hand, 4 or more $\mathrm{pN}+$ was the best prognostic cut-off value in positive necks (AUC $=0.636 ; \mathrm{p}=0.012$ and AUC $=0.579 ; \mathrm{p}=0.156$, respectively). OS and RFS worsened stepwise in OSCCs with DOI $<5 \mathrm{~mm}, \geq 5$ and $<10 \mathrm{~mm}, \geq 10$ and $<20 \mathrm{~mm}$, and $\geq 20 \mathrm{~mm}$ ( $\mathrm{p}=0.0006$ and $\mathrm{p}=0.106$, respectively; Fig. 3 ). The $20 \mathrm{~mm}$ cut-off was used instead of $22 \mathrm{~mm}$ to simplify a potential implementation into the T-classification. OS and RFS worsened stepwise in OSCCs with no nodal metastasis, less than 4 nodal metastases, and 4 or more involved nodes $(\mathrm{p}<0.0001$ and $\mathrm{p}<0.0001$, respectively; Fig. 3).

\section{Discussion}

In our study, the reallocation of patients according to the 8th edition of the TNM staging system demonstrated a remarkable impact on the distribution of $\mathrm{T}, \mathrm{N}$ categories, and stage of OSCC, which changed in $59.2 \%, 20.5 \%$, and $49.1 \%$ within the present series, respectively, compared to the 7 th edition. These changes are of paramount importance when considering that $\mathrm{T}$ and $\mathrm{N}$ categories guide loco-regional treatment in patients without distant metastasis. The downstaging $\mathrm{T}_{4 \mathrm{a} \rightarrow 3}(36.1 \%)$ and the upstaging $\mathrm{T}_{1 / 2 \rightarrow 3}(16.2 \%)$ were the most relevant modifications of $\mathrm{T}$ category as an effect of the exclusion of lingual extrinsic musculature invasion and inclusion of the DOI parameter for T assignment. Accordingly, pT3 experienced a remarkable shift from $3.3 \%$ to $46.6 \%$. N category changed due to the presence of ENE, which caused a shifting to the pN3b category in $20.5 \%$ of patients, whereas in only $6(2.5 \%)$ was the N-status uplifted from pN1 to pN2a. pN3 patients passed from being absent to being diagnosed in $22.1 \%$ of cases [16]. Overall, these changes produced downstaging and upstaging in $17.1 \%$ and $41.5 \%$ of OSCCs, respectively. More specifically, 20 patients $(9.8 \%)$ would have been shifted from stage I-II "early disease" to stage III-IV "advanced disease", while only 3 (1.5\%) would have been downstaged. All these modifications in $\mathrm{T}$ and $\mathrm{N}$ classification and staging are consistent with other published reports $[17,18]$. Such an important stage migration, and in particular the shift from early to advanced disease, convey relevant implications in treatment planning. Of note, a considerable number of patients would receive intensified therapeutic regimens according to the new TNM classification system. The soundness of this shift should be however validated in future, prospective series.

Although the population size of the present study is limited, the homogeneity of treatment and the direct source of information ensured the reliability of our data. The most relevant findings are hereby clustered in "gains", "losses", and "missing information" with the aim of providing an overview of the pros and cons of the current TNM edition for OSCC classification and presenting evidence for further improvements.

\section{What is gained?}

The new $\mathrm{T}$ classification system of OSCC may improve patient stratification according to OS. Specifically, tumors remaining T1/2 and $\mathrm{T} 4 \mathrm{a}$ are associated with the best and worst outcomes, respectively, while several OSCCs previously defined as $\mathrm{T} 1 / 2$ or T4a and now assigned to T3 category share a homogeneous intermediate long-term OS trend (Fig. 1). Coherently, T4a tumors are associated with the poorest results when focusing on loco-regional control. These data are in accordance with literature, as several reports from all over the world demonstrated higher predictive accuracy of the 8th TNM edition [17-24].

Pathologic N3b category was an important negative prognosticator. In fact, patients with N3b tumors had dismal OS and DSS due to the increased rate of distant recurrence, independently of other prognostic factors. Interestingly, pN3b category was more predictive of poor prognosis than ENE alone. This suggests that a high number of positive nodes has a prognostic weight even in patients with ENE. In fact, patients with a single nodal metastasis with ENE were not significantly associated with poor prognosis. Of note, these patients are a minority, with most cases of ENE being observed in necks with multiple nodal metastases. As a side note, a criticism on pN3a allocation must be made in view of its rarity (it is absent in our series); a single pN3 category 


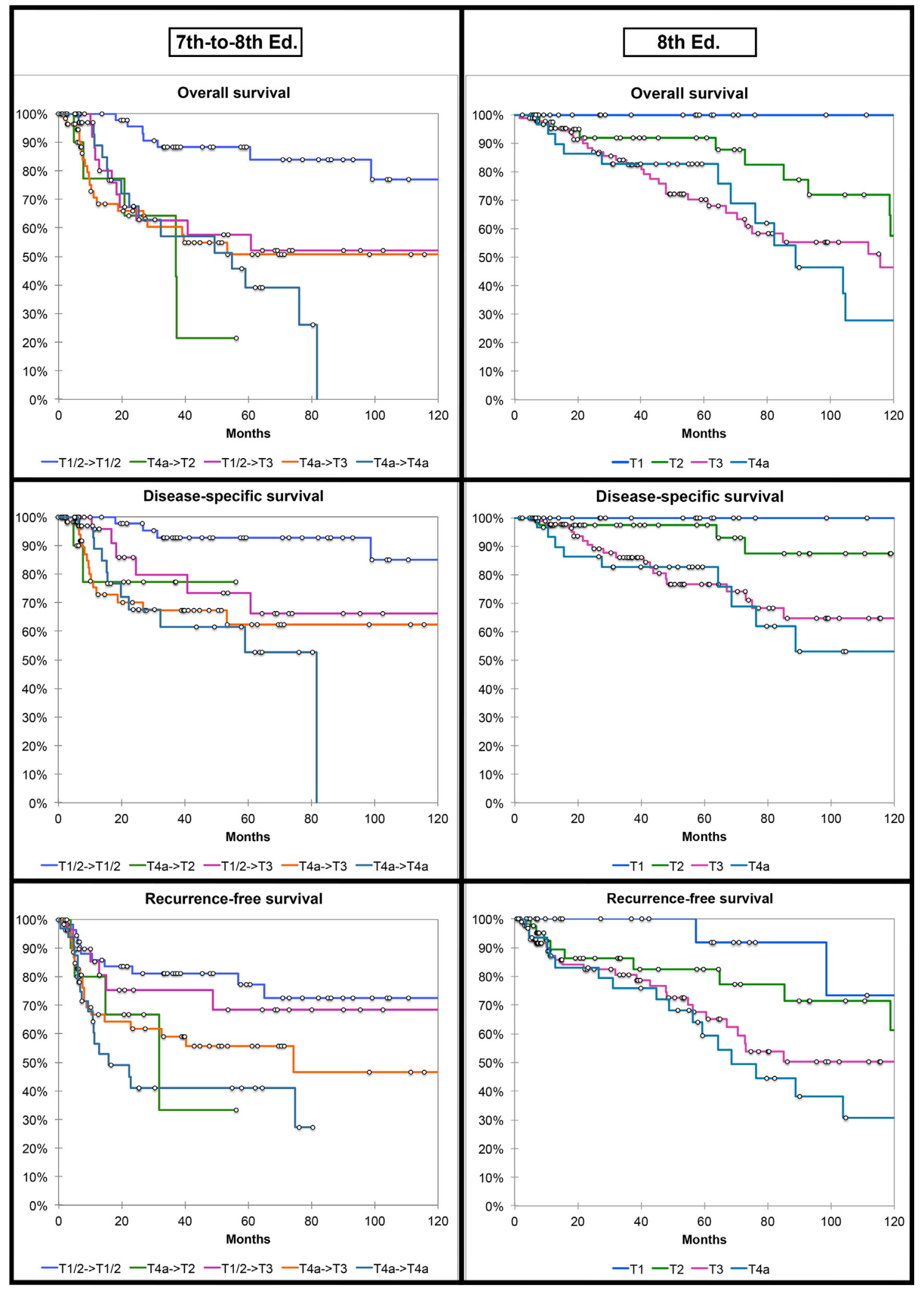

Fig. 1. Kaplan-Meier plots illustrating overall, disease-specific, and recurrence-free survival according to $\mathrm{T}$ category modification passing from the 7th to the 8th TNM edition (left column) and according to T category of the 8th TNM edition (right column).

would be simpler and still appropriate [25].

Perineural invasion was independently associated with worse DRFS. The 8th TNM edition systematically assesses this feature, thus ensuring a more consistent profiling of the disease and contributing, for the future, to possibly segregate lesions with this risk factor from those without. 


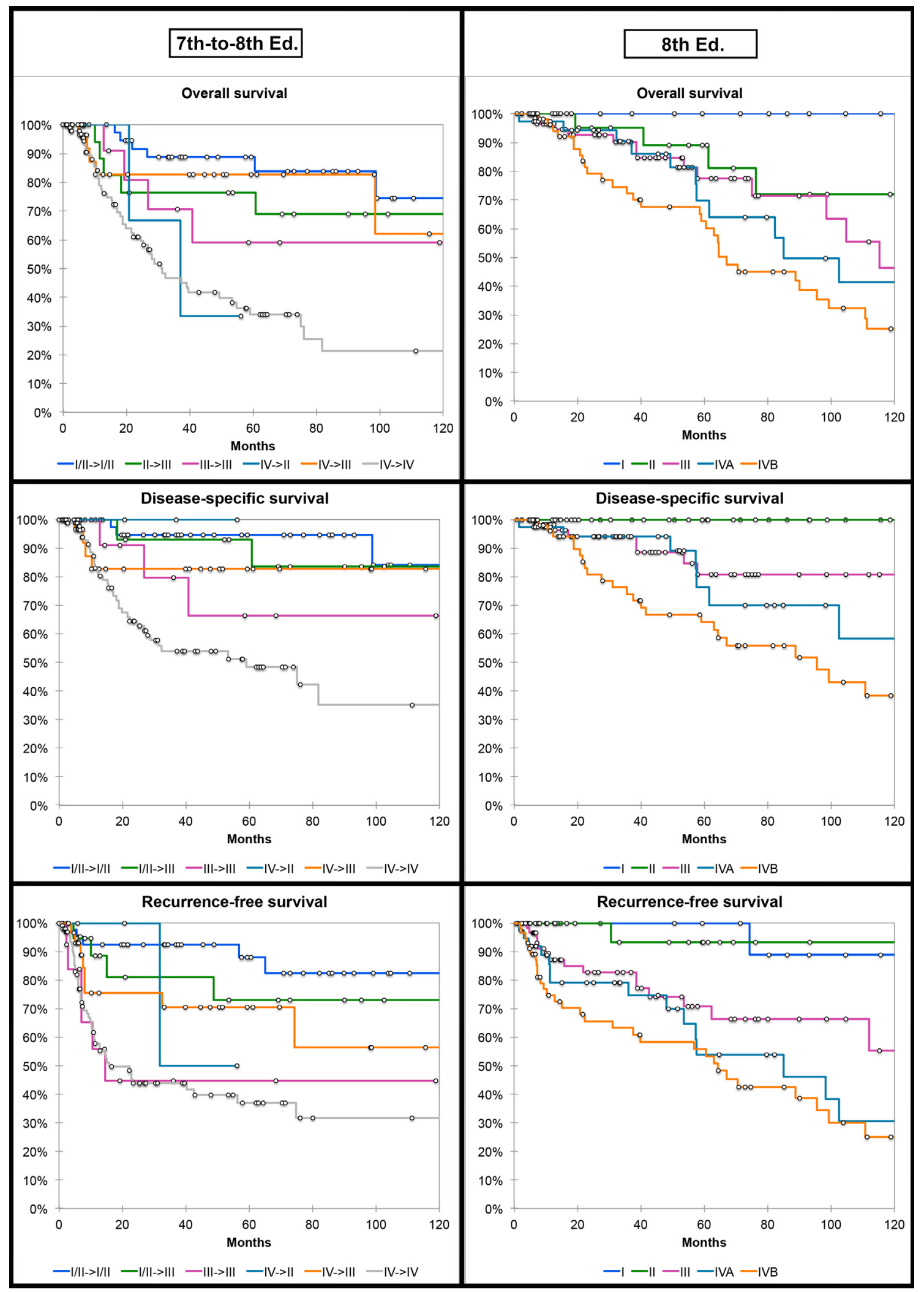

Fig. 2. Kaplan-Meier plots illustrating overall, disease-specific, and recurrence-free survival according to stage modification passing from the 7th to the 8th TNM edition (left column) and according to stage of the 8th TNM edition (right column).

\section{What is lost?}

When analyzing the probability and pattern of recurrence, T3 OSCCs according to the 8th edition showed a heterogeneous behavior, which conflicts with what previously mentioned with respect to OS. In fact, tumors defined as T4a according to the 7th edition were associated with a high propensity for recurrence regardless of reassignment to the T2, T3, or T4a category with the new system (Fig. 1). The pattern of 

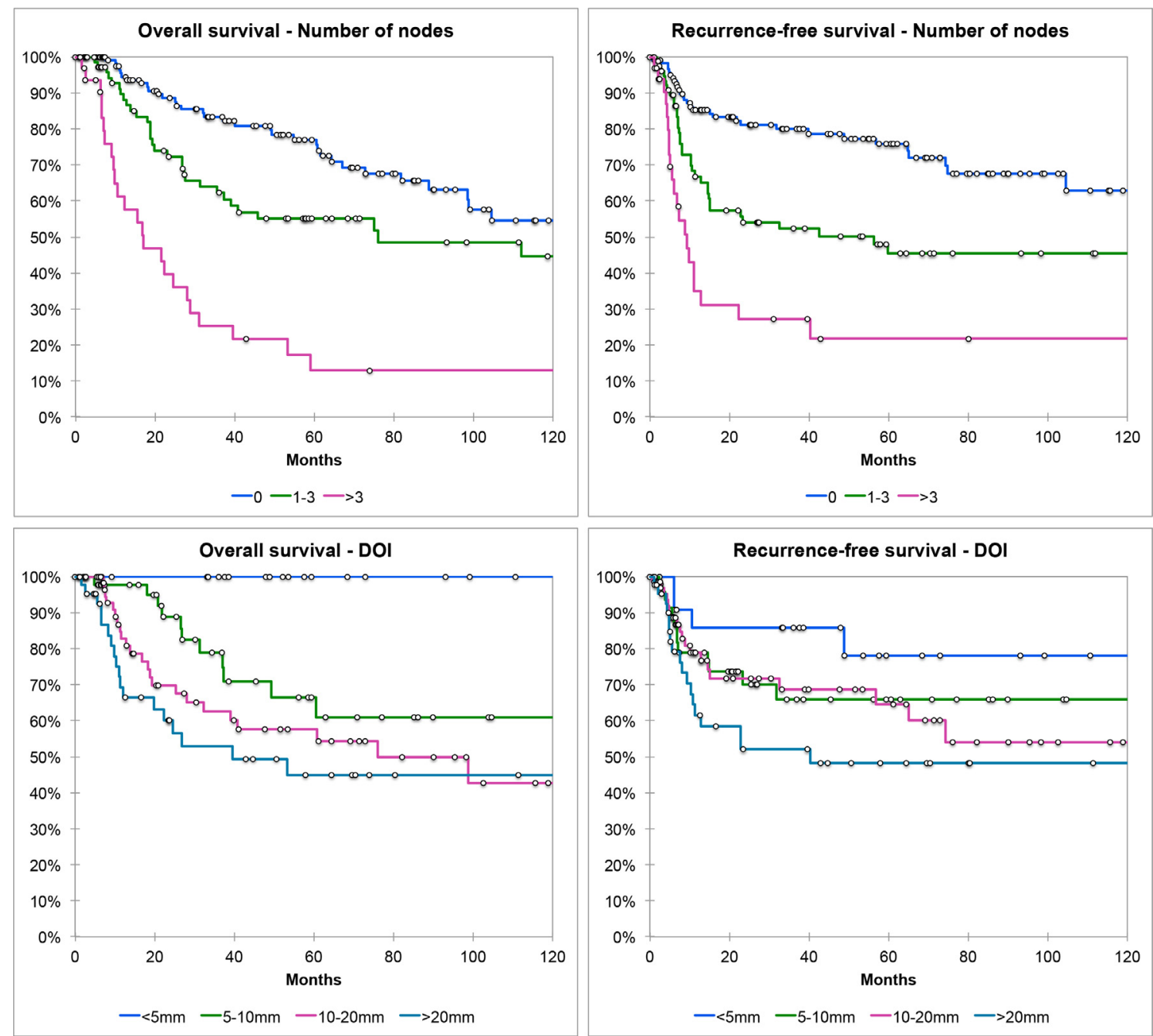

Fig. 3. Kaplan-Meier plots showing the stratification of overall and recurrence-free survival according to the number of involved nodes and depth of invasion (DOI).

recurrence varied from $\mathrm{T}_{4 \mathrm{a} \rightarrow 3}$ tumors, showing preeminently regional and distant failure, to $\mathrm{T}_{4 \mathrm{a} \rightarrow 4 \mathrm{a}}$ OSCCs, which typically recurred locoregionally (Supplementary Fig. 1). Overall, these subsets of tumors, according to the criteria of $\mathrm{T}$ classification, correspond to OSCCs that extended to the extrinsic tongue muscles $\left(\mathrm{T}_{4 \mathrm{a} \rightarrow 3}\right.$ and $\left.\mathrm{T}_{4 \mathrm{a} \rightarrow 2}\right)$ and/or the skin/bone framework surrounding the oral cavity $\left(\mathrm{T}_{4 \mathrm{a} \rightarrow 4 \mathrm{a}}\right)$. The poor prognosis shown by $\mathrm{T}_{4 \mathrm{a} \rightarrow 3}$ OSCCs somehow conflicts with grouping these tumors together with $\mathrm{T}_{1 / 2 \rightarrow 3}$ cases, which are those redefined as T3 due to DOI $>10 \mathrm{~mm}$ without invasion of bone and/or skin. The different behavior of these cancers is likely related to the disease load in the nodal basin, which is substantially higher for $\mathrm{T}_{4 \mathrm{a} \rightarrow 3}$ and $\mathrm{T}_{4 \mathrm{a} \rightarrow 2}$ OSCCs compared to other subsets (Table 3), and to the higher DOI observed in $\mathrm{T}_{4 \mathrm{a} \rightarrow 3}$ tumors (median, $19.5 \mathrm{~mm}$; Table 4). This concept reflects the debate on the role of extrinsic musculature invasion in defining $\mathrm{T}$ category. One can argue that definition of invasion of the extrinsic musculature of the tongue is mostly a clinical-radiological data and is difficult to assess on pathological examination. However, tumors previously labeled as T4a due to invasion of the extrinsic lingual muscles clearly have a different nodal status at presentation and a more ominous prognosis compared to those not having this pathological feature. As already demonstrated elsewhere [6], DOI is a potential surrogate of this feature, but possibly deserves a further stratification for subsites and for T4a classification.
What is missing?

The evidence that T3 according to the 8th Edition behave heterogeneously could be related to the absence of a DOI value determining the shift to the T4a category. According to the ROC and survival analysis, $20 \mathrm{~mm}$ could be a reasonable cut-off to further stratify OSCCs with DOI $>10 \mathrm{~mm}$ into T3 and T4a. This is supported by the evidence that OS continues to be independently affected by thickness of invasion even beyond $10 \mathrm{~mm}$, and it is in line with the value proposed by Liao et al. $[26,27]$. From the anatomical point of view, it is worth remembering that a tongue tumor thickness $>20 \mathrm{~mm}$ potentially lead to subtotal if not total glossectomy.

The number of nodal metastases was independently associated with all survival outcomes, with 4 nodes resulting as the optimal cut-off to stratify patients. This finding perfectly aligns with that of Ho et al. [28], who reported that the number of nodal metastases serves as critical prognostic information that is capable of eclipsing other traditional prognosticators. The risk of death increased by $13 \%$ for each nodal metastasis according to the multivariate model. This was due to an increased risk for local, regional, and distant recurrence of $14 \%, 18 \%$, and $13 \%$ for each involved node. These findings corroborate the acknowledged belief that the load of disease in the neck is a predominant prognosticator in OSCC, with the count of positive nodes being a much better predictor than laterality. Count of nodal metastases was demonstrated to be at least as reliable and repeatable as lymph nodal ratio, which in turn is considerably affected by the extent of neck 
dissection and processing protocol of the surgical specimen [29]. Moreover, the number of involved nodes was found to reliably predict the benefit from concomitant chemotherapy in the adjuvant setting [30].

Currently, perineural spread is systematically assessed but does not bring the tumor to a higher stage. However, the risk of distant relapse during follow-up was more than doubled in case of perineural growth, regardless of other factors. In previous studies, perineural invasion improved the accuracy of prognostication when combined with other clinical-pathological factors (tumor grade, thickness, volume, nodal status, bone infiltration, neutrophils-to-lymphocytes ratio) [31-34]. This supports the possibility to emphasize the weight of perineural spread in the decision-making for adjuvant treatments. However, dedicated studies are mandatory before reaching firm conclusions on this topic.

\section{$T$ classification and natural history of OSCC}

Finally, the results of the present study can help in depicting the natural history of OSCC. In the early phases $\left(\mathrm{T}_{1 / 2 \rightarrow 1 / 2}\right)$, OSCC grows superficially, leading to a $26.7 \%$ rate of nodal involvement, mostly consisting of single metastasis [35]. Patients usually have a favorable prognosis even with single-modality treatment. Subsequently, the tumor deepens into the surrounding tissues $\left(\mathrm{T}_{1 / 2 \rightarrow 3}\right)$, nearly doubling the frequency and load of neck disease. The 8th TNM Edition reliably highlights this aspect by upstaging cases previously defined as T1/2 $[36,37]$. At the last stage of its natural history, OSCC reaches deeply located soft tissues and/or bony structures $\left(\mathrm{T}_{4 \mathrm{a} \rightarrow 2}, \mathrm{~T}_{4 \mathrm{a} \rightarrow 3}\right.$, and $\left.\mathrm{T}_{4 \mathrm{a} \rightarrow 4 \mathrm{a}}\right)$. In tumors invading the deep soft tissues (i.e. those previously defined T4a due to invasion of the extrinsic tongue musculature), the rate of nodal involvement is as high as $60.0-66.1 \%$, with ENE being detected in $41.1-50.0 \%$ of positive necks. These tumors have the highest propensity for regional and distant recurrence, thereby deserving a proportionally aggressive treatment that frequently consists of surgery with adjuvant (chemo)RT. In our opinion, downstaging the $\mathrm{T}$ category in these tumors might not adequately reflect their advanced phase of growth and consequent treatment requirements. As already mentioned, this aspect could be corrected by introducing a DOI cut-off for T4a tumors of $>20 \mathrm{~mm}$. OSCCs extended to the maxillofacial skeleton or skin (i.e. invariably classified as $\mathrm{T} 4 \mathrm{a}$ ) do not show a considerable increase in terms of neck involvement with respect to $T_{1 / 2 \rightarrow 3}$ tumors. Nevertheless, these cancers are more prone to recur locoregionally during follow-up. Further studies are needed to depict the biological characteristics of tumors in these different stages, in order to gain information about the molecular derangements leading to tumor growth and provide new insights for a more tailored clinical approach.

\section{Conclusion}

With the limitations ensuing from the retrospective nature and restricted sample size of this study, our findings suggest that the introduction of the last TNM edition has provided some steps forward in delineating tumor characteristics and outcomes. Future revisions should address the needs which are emerging for further refinements. Based on our data, DOI $>20 \mathrm{~mm}$ for T4 definition and number of positive nodes for $\mathrm{N}$ classification are the most urgent factors to be implemented.

\section{Declaration of Competing Interest}

The authors declare that they have no known competing financial interests or personal relationships that could have appeared to influence the work reported in this paper.

\section{Appendix A. Supplementary material}

Supplementary data to this article can be found online at https:// doi.org/10.1016/j.oraloncology.2020.104937.

\section{References}

[1] Ferlay J, Soerjomataram I, Dikshit R, Eser S, Mathers C, Rebelo M, et al. Cancer incidence and mortality worldwide: Sources, methods and major patterns in GLOBOCAN 2012. Int J Cancer 2015;136:E359-86. https://doi.org/10.1002/ijc. 29210.

[2] National Cancer Institute. National Cancer Institute SEER cancer statistics review 1975-2012. SEER cancer stat rev 1975-2012. Natl Cancer Inst 2015:1992-2012.

[3] Edge SB, Compton CC. The American joint committee on cancer: the 7th edition of the AJCC cancer staging manual and the future of TNM. Ann Surg Oncol 2010;17(6):1471-4. https://doi.org/10.1245/s10434-010-0985-4.

[4] Colevas AD, Yom SS, Pfister DG, Spencer S, Adelstein D, Adkins D, et al. NCCN guidelines insights: head and neck cancers version 1.2018. J Natl Compr Cancer Netw 2018;16:479-90. https://doi.org/10.6004/jnccn.2018.0026.

[5] Huang SH, O'Sullivan B. Overview of the 8th edition TNM classification for head and neck cancer. Curr Treat Options Oncol 2017;18(7). https://doi.org/10.1007/ s11864-017-0484-y.

[6] Piazza C, Montalto N, Paderno A, Taglietti V, Nicolai P. Is it time to incorporate 'depth of infiltration' in the T staging of oral tongue and floor of mouth cancer? Curr Opin Otolaryngol Head Neck Surg 2014;22:81-9. https://doi.org/10.1097/MOO. 0000000000000038.

[7] Tam S, Amit M, Zafereo M, Bell D, Weber RS. Depth of invasion as a predictor of nodal disease and survival in patients with oral tongue squamous cell carcinoma. Head Neck 2018. https://doi.org/10.1002/hed.25506.

[8] Ebrahimi A, Gil Z, Amit M, Yen T-C, Liao C-T, Chaturvedi P, et al. Primary tumor staging for oral cancer and a proposed modification incorporating depth of invasion. JAMA Otolaryngol Neck Surg 2014;140:1138. https://doi.org/10.1001/jamaoto. 2014.1548.

[9] Shaw RJ, Lowe D, Woolgar JA, Brown JS, Vaughan ED, Evans C, et al. Extracapsular spread in oral squamous cell carcinoma. Head Neck 2009;32. https://doi.org/10. 1002/hed.21244. NA-NA.

[10] Woolgar JA, Rogers SN, Lowe D, Brown JS, Vaughan ED. Cervical lymph node metastasis in oral cancer: the importance of even microscopic extracapsular spread. Oral Oncol 2003;39:130-7.

[11] Adelstein D, Gillison ML, Pfister DG, Spencer S, Adkins D, Brizel DM, et al. NCCN guidelines insights: head and neck cancers, version 2.2017. J Natl Compr Canc Netw 2017;15:761-70. https://doi.org/10.6004/jnccn.2017.0101.

[12] Alterio D, Bacigalupo A, Cantù G, Cerrotta A, De Sanctis V, Grandi C, et al. Linee guida - Tumori della testa e del collo. Aiom 2016.

[13] Amin MB, Greene FL, Edge SB, Compton CC, Gershenwald JE, Brookland RK, Meyer L, Gress DM, Byrd DR, Winchester DP. The Eighth Edition AJCC cancer staging manual: continuing to build a bridge from a population-based to a more "personalized" approach to cancer staging: The Eighth Edition AJCC Cancer Staging Manual. CA Cancer J Clin 2017;67(2):93-9. https://doi.org/10.3322/caac.21388.

[14] El-Naggar AK, Chan JKC, Rubin Grandis J, Takata T, Slootweg PJ, International Agency for Research on Cancer. WHO classification of head and neck tumours; n.d.

[15] Harrell FE. Regression modeling strategies: with applications to linear models, logistic regression, and survival analysis. New York: Springer; 2001.

[16] Lee NCJ, Eskander A, Park HS, Mehra S, Burtness BA, Husain Z. Pathologic staging changes in oral cavity squamous cell carcinoma: Stage migration and implications for adjuvant treatment. Cancer 2019;125:2975-83. https://doi.org/10.1002/cncr. 32161.

[17] Kano S, Sakashita T, Tsushima N, Mizumachi T, Nakazono A, Suzuki T, Yasukawa S, Homma A. Validation of the 8th edition of the AJCC/UICC TNM staging system for tongue squamous cell carcinoma. Int J Clin Oncol 2018;23(5):844-50. https://doi. org/10.1007/s10147-018-1276-5.

[18] Singhavi HR, Chakrabarti S, Singh A, Mair M, Bhattacharjee A, Shetty R, et al. Comparison of the seventh and eighth editions American Joint Committee Cancer classification system in oral cavity squamous cell cancers. Int J Cancer 2019. https://doi.org/10.1002/ijc.32720.

[19] Vuity D, McMahon J, Takhiuddin S, Slinger C, McLellan D, Wales C, MacIver C, Thomson E, McCaul J, Hislop S, Lamb C, Stalker E, Young D. Is the 8th edition of the Union for International Cancer Control staging of oral cancer good enough? $\mathrm{Br} \mathrm{J}$ Oral Maxillofac Surg 2018;56(4):272-7. https://doi.org/10.1016/j.bjoms.2018.01. 017.

[20] Pollaers K, Hinton-Bayre A, Friedland PL, Farah CS. AJCC 8th Edition oral cavity squamous cell carcinoma staging - Is it an improvement on the AJCC 7th Edition? Oral Oncol 2018;82:23-8. https://doi.org/10.1016/j.oraloncology.2018.04.018.

[21] Tirelli G, Gatto A, Boscolo Nata F, Bussani R, Piccinato A, Marcuzzo AV, et al. Prognosis of oral cancer: a comparison of the staging systems given in the 7 th and 8th editions of the American Joint Committee on Cancer Staging Manual. Br J Oral Maxillofac Surg 2018;56:8-13. https://doi.org/10.1016/j.bjoms.2017.11.009.

[22] Cramer JD, Reddy A, Ferris RL, Duvvuri U, Samant S. Comparison of the seventh and eighth edition American joint committee on cancer oral cavity staging systems: validation of oral cancer staging system. The Laryngoscope 2018;128(10):2351-60. https://doi.org/10.1002/lary.27205.

[23] Matos LL, Dedivitis RA, Kulcsar MAV, de Mello ES, Alves VAF, Cernea CR. External validation of the AJCC Cancer Staging Manual, 8th edition, in an independent cohort of oral cancer patients. Oral Oncol 2017;71:47-53. https://doi.org/10.1016/j. 
oraloncology.2017.05.020.

[24] Murthy S, Low T-H, Subramaniam N, Balasubramanian D, Sivakumaran V, Anand A, Vijayan SN, Nambiar A, Thankappan K, Iyer S. Validation of the eighth edition AJCC staging system in early T1 to T2 oral squamous cell carcinoma: MURTHY et al. J Surg Oncol 2019;119(4):449-54. https://doi.org/10.1002/jso.25348.

[25] García J, López M, López L, Bagué S, Granell E, Quer M, León X. Validation of the pathological classification of lymph node metastasis for head and neck tumors according to the 8th edition of the TNM Classification of Malignant Tumors. Oral Oncol 2017;70:29-33. https://doi.org/10.1016/j.oraloncology.2017.05.003.

[26] Chang B, He W, Ouyang H, Peng J, Shen L, Wang A, et al. A prognostic nomogram incorporating depth of tumor invasion to predict long-term overall survival for tongue squamous cell carcinoma with R0 resection. J Cancer 2018;9:2107-15. https://doi.org/10.7150/jca.24530.

[27] Liao C-T, Lee L-Y, Hsueh C, Lin C-Y, Fan K-H, Wang H-M, et al. Oral cavity cancer staging system. Ann Surg Oncol 2018;2019. https://doi.org/10.1245/s10434-01907576-5.

[28] Ho AS, Kim S, Tighiouart M, Gudino C, Mita A, Scher KS, et al. Metastatic lymph node burden and survival in oral cavity cancer. J Clin Oncol 2017;35:3601-9. https://doi.org/10.1200/JCO.2016.71.1176.

[29] de Ridder M, Marres CCM, Smeele LE, van den Brekel MWM, Hauptmann M, Balm AJM, et al. A critical evaluation of lymph node ratio in head and neck cancer. Virchows Arch 2016;469:635-41. https://doi.org/10.1007/s00428-016-2015-9.

[30] Feng Z, Xu QS, Wang C, Li JZ, Mao MH, Li H, et al. Lymph node ratio is associated with adverse clinicopathological features and is a crucial nodal parameter for oral and oropharyngeal cancer. Sci Rep 2017;7:6708. https://doi.org/10.1038/s41598017-07134-7.

[31] Bobdey S, Mair M, Nair S, Nair D, Balasubramaniam G, Chaturvedi P. A Nomogram based prognostic score that is superior to conventional TNM staging in predicting outcome of surgically treated T4 buccal mucosa cancer: Time to think beyond TNM. Oral Oncol 2018;81:10-5. https://doi.org/10.1016/j.oraloncology.2018.04.002.

[32] Lee C-C, Huang C-Y, Lin Y-S, Chang K-P, Chi C-C, Lin M-Y, et al. Prognostic performance of a new staging category to improve discrimination of disease-specific survival in nonmetastatic oral cancer. JAMA Otolaryngol Neck Surg 2017;143:395 https://doi.org/10.1001/jamaoto.2016.3802.

[33] Mair M, Nair D, Nair S, Malik A, Mishra A, Kannan S, et al. Comparison of tumor volume, thickness, and $\mathrm{T}$ classification as predictors of outcomes in surgically treated squamous cell carcinoma of the oral tongue. Head Neck 2018;40:1667-75. https://doi.org/10.1002/hed.25161.

[34] Subramaniam N, Murthy S, Balasubramanian D, Low T-H, Vidhyadharan S, Clark JR, Thankappan K, Iyer S. Adverse pathologic features in T1/2 oral squamous cell carcinoma classified by the American Joint Committee on Cancer eighth edition and implications for treatment. Head Neck 2018;40(10):2123-8. https://doi.org/10. 1002/hed.25168.

[35] den Toom IJ, Janssen LM, van Es RJJ, Karagozoglu KH, de Keizer B, van Weert S, et al. Depth of invasion in patients with early stage oral cancer staged by sentinel node biopsy. Head Neck 2019. https://doi.org/10.1002/hed.25665.

[36] Amit M, Tam S, Takahashi H, Choi KY, Zafereo M, Bell D, Weber RS. Prognostic performance of the American Joint Committee on Cancer 8th edition of the TNM staging system in patients with early oral tongue cancer. Head Neck 2019;41(5):1270-6. https://doi.org/10.1002/hed.v41.510.1002/hed.25553.

[37] Jain D, Dravid C, Singla A, Kumari S, Grover RK. Comparison of the seventh and eighth editions of the American joint committee on cancer $\mathrm{pT}$ and $\mathrm{pN}$ classifications as predictors of survival in patients with oral squamous cell carcinoma. Am J Clin Pathol 2019;151:292-301. https://doi.org/10.1093/ajcp/aqy143. 